\title{
Engineering minerals for performance applications: an industrial perspective ${ }^{\dagger}$
}

\author{
J. S. PHIPPS \\ Imerys Minerals Limited, Par Moor Centre, Par, Cornwall PL24 2SQ, UK
}

(Received 17 December 2013; revised 1 February 2014; Editor: George Christidis)

\begin{abstract}
To a mineralogist, minerals are defined primarily by their crystal structure and chemical composition. Many minerals of industrial importance retain this identity in their final application. For the producer and end user, the physical properties of these industrial mineral products such as size and shape distribution, refractive index, density, hardness, refractoriness and colour are of primary importance, since it is the combination of these, together with its surface chemistry, which gives the mineral its functionality. As a result, minerals which are very different in structure and origin but have many similar physical properties, such as kaolin and calcium carbonate, are often used in very similar roles and in similar applications.

Examples of mineral use in diverse applications such as paper, paints and coatings, polymers and films show how the physical properties of different minerals are exploited and engineered to provide optical, mechanical and rheological performance and to minimise cost. Industrial mineral producers have been manipulating these properties for many decades and continue to do so in search of improved performance and new applications. As new high performance materials become more commonplace, the challenge is to find new ways of transforming minerals to provide the necessary functionality for them.
\end{abstract}

KEYWORDS: engineering minerals, paper manufacture, paints, coatings, polymers, films, optical properties, mechanical properties, rheological performance.

The term 'industrial mineral' can, in principle, be used to describe any material that is mined at large scale, although most accepted definitions do not include ores (Bates, 1994). Ores are minerals which are mined specifically for the elements they contain, which most commonly are metals, and from which those elements will be extracted chemically. These represent probably the largest category of mined minerals. The structure and properties of the host mineral ore are only of industrial interest insofar as they influence the process required to extract the desired elements and the ease with which this can be done.

* E-mail: Jon.phipps@imerys.com

DOI: 10.1180 /claymin.2014.049.1.01
For the purposes of this paper we will classify non-ore industrial minerals into two different categories. The first category we shall call 'reactive minerals'. These are mined specifically for the mineral they contain rather than its constituent elements. The whole mineral is used in its final application, but becomes chemically transformed along the way. Typical examples of reactive minerals are those used in ceramics and refractories - generally the mineral is transformed by firing, often in the presence of fluxes and other minerals.

The second category of industrial minerals we shall call 'functional minerals'. These are minerals

$\dagger$ Presented at the Mineralogical Society conference 'Minerals for Life', Edinburgh University, 2013. 
which remain chemically unchanged in their final application, and which are the subject of this paper. Sand and aggregates fit within this definition and represent the largest volume, but we shall focus on those minerals which are comprised of particles roughly in the micron-sized range and which are engineered mainly for use in functional materials. The main aim of the paper will be to give the reader an understanding of the wide range of applications of these minerals, their attributes and how they can be engineered to improve their performance.

Table 1 shows a list of the major functional minerals and their estimated worldwide consumption. Their major application is as fillers and additives for functional materials, but there are also other more specialised uses such as in particle beds for filtration (diatomite and perlite), as weighting (densifying) agents for drilling fluids (baryte), rheology control (bentonite) and in electronics (graphite).

\section{CHOOSING AND ENGINEERING MINERALS FOR SPECIFIC APPLICATIONS}

The major property of interest of an industrial mineral for its applications is not generally its specific structure (chemical composition, crystal lattice, etc.), except insofar as it determines the mineral's physical properties such as refractive index, density, hardness, colour or electrical/ thermal conductivity. These are intrinsic properties of the mineral which cannot be changed without chemical transformation, and they determine whether a mineral is suitable for an application. Functional industrial minerals are almost always composed of fine particles, typically in the micron/ submicron range. Physicochemical properties of a mineral product that are related to its particulate structure, such as particle size distribution, particle shape, surface area, surface chemistry and treatment, state of aggregation, impurities etc. can be engineered for specific applications, and this is the job of the industrial mineral supplier and the source of value and differentiation of their products.

The particle size distribution of industrial mineral products is the most important attribute that can be manipulated. Mineral particles come in a variety of shapes, and so defining their particle size is not straightforward (Hart et al., 2011). Mostly it is done pragmatically according to the technique that is used to measure it. The most common techniques used for measuring particle size distribution in the micron and submicron range are sedimentation, static light scattering (laser diffraction) dynamic

TABLE 1. Major functional industrial minerals, their estimated annual worldwide consumption and typical uses.

\begin{tabular}{|c|c|c|c|}
\hline Mineral & $\begin{array}{c}\text { Worldwide } \\
\text { consumption } \\
2010 \text { (ktonnes) }\end{array}$ & Typical applications & Function \\
\hline Calcium carbonate & 67,000 & $\begin{array}{l}\text { Paper, plastics, paints and coatings, } \\
\text { rubber }\end{array}$ & $\begin{array}{l}\text { Filler,pigment, glossing agent, } \\
\text { reinforcement, barrier properties }\end{array}$ \\
\hline Kaolin & 23,000 & & \\
\hline Talc & 6800 & & \\
\hline Vermiculite & 540 & & \\
\hline Wollastonite & 330 & & \\
\hline Mica & 310 & & \\
\hline Perlite & 1700 & $\begin{array}{l}\text { Filtration, paints and coatings, } \\
\text { construction }\end{array}$ & \\
\hline Diatomite & 1400 & & \\
\hline Bentonite & 11,000 & Viscosifier, absorbent & \\
\hline Graphite & 540 & $\begin{array}{l}\text { Batteries, friction components, } \\
\text { refractory linings, plastics }\end{array}$ & $\begin{array}{l}\text { Electrical/thermal conductor, } \\
\text { electrode, lubricant, refractory }\end{array}$ \\
\hline Baryte & 6600 & Coatings, oilfield drilling fluids & Pigment, weighting agent \\
\hline
\end{tabular}

Sources - Industrial Minerals magazine, USGS, Roskill 
light scattering (photon correlation spectroscopy) and electrical impedance (Coulter counter). Each measures a particular property of the particle, and defines size according to an equivalent spherical diameter (esd) (Jennings \& Parslow, 1988). This is the diameter of a sphere of the same density as the mineral which would appear to be the same size as the particle in the technique being used. It is important to note that a particle which reports at a given esd by sedimentation would not necessarily report at the same esd by light scattering, because the two techniques measure different properties of the particles which are each dependent upon the particle shape in different ways. Indeed, the differences between the results of the different measurements can be used to extract information on particle morphology (Slepetys \& Cleland, 1993).

For particles greater than a few microns in size, it is becoming common to use microscopy in combination with high speed image analysis to measure size distributions. Because the actual dimensions of each particle in the sample are analysed in this way, size can be defined however the user chooses, and very rich information on the morphology of the material can be obtained (Brown et al., 2005). In order to count sufficient particles to obtain a statistically significant distribution, a stream of particles flows past the microscope, which captures many images per second for analysis. Unfortunately this technique is not often used to characterise functional minerals because the particles are too small for optical microscopy. Although suitable images could, in principle, be produced using electron microscopy, only images of static particles can be captured, and the time required to collect enough images for a representative distribution is generally prohibitive.

The particle size distributions of natural minerals, and to a large extent engineered ones as well, are very often approximately $\log$ normal. This is convenient because a log normal distribution can be represented by just two parameters - a median size and a steepness. There is no accepted standard definition of steepness, but suppliers and users normally define it in terms of the ratio between two positions on the cumulative distribution curve. These positions are usually named as for example 'd 30 ', which is the size at which $30 \%$ of the particles in the distribution are smaller and $70 \%$ are larger. Steepness may therefore be defined as $\mathrm{d} 30$ / d70, d16/d84, etc. d16/d84 is often a preferred measure because the two d values are one standard deviation either side of the median. For the examples in this paper we define it as $100 \times$ d30/d70 (Fig. 1); these values are easy to measure accurately by sedimentation for most functional minerals and it gives a scale from 0 to 100 in which 100 is a monodisperse distribution and 0 is

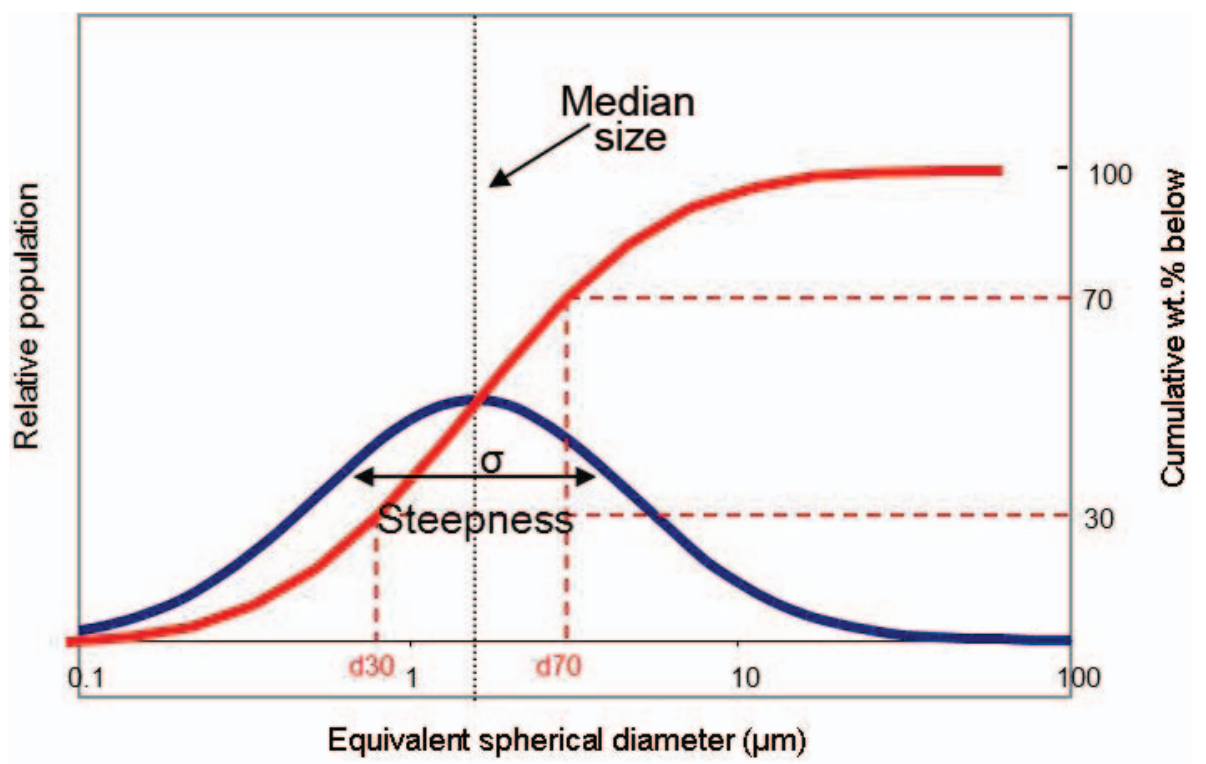

FIG. 1. Log Normal distribution - cumulative and population curves, median size and d30/d70 steepness. 
infinitely broad. In addition, $\mathrm{d} 30$ and $\mathrm{d} 70$ are separated by approximately one standard deviation. Schematic examples of broad and narrow distributions found in industrial minerals are shown in Fig. 2. Note how a steep distribution (typical of a precipitated calcium carbonate) with a fine median size $0.75 \mu \mathrm{m}$ has fewer ultrafines (particles with esd $<0.3 \mu \mathrm{m}$ ) than a broad distribution with a much larger median size of $2 \mu \mathrm{m}$ (typical of a singlestage refined kaolin or a ground calcium carbonate). This can be critical to performance in many applications.

\section{SOME COMMON APPLICATIONS OF INDUSTRIAL MINERALS}

To illustrate the way industrial minerals are engineered for specific applications, we will examine a range of examples. Although each application has its own particular requirements, there are many common material properties (such as light scattering, strength and porosity) that are influenced by the addition of minerals and are of critical importance.

\section{Application 1 - uncoated paper}

Paper is one of the largest users of industrial minerals. They are added primarily to improve optical and printing properties, both as fillers and as the major part of paper coatings. Uncoated papers make up most of the lower quality grades and may be very heavily loaded with minerals (Paulapuro, 2000). Some examples are in office printing and photocopy paper which is typically $20-25 \%$ carbonate by weight, and 'supercalendered' magazine papers which can be up to $40 \%$ kaolin.

Figure 3 is a scanning electron microscope image which shows the structure of a typical copy paper, illustrating the relative scale of the fibres and the mineral filler (calcium carbonate) particles. The latter can be seen clustered together between the large fibres. Calcium carbonate and cellulose fibres have quite similar refractive indices, but the filler particles scatter light much more strongly because they provide more surface at which there is a refractive index contrast with the surrounding medium (air), and because the particles and the pores between them are close to wavelength of light. However, the addition of fillers always reduces the strength of the paper (Bown, 1985, 1995), because this is derived from hydrogen bonding between the fibres which are drawn into close contact by surface tension forces during drying, and unfortunately filler particles get between the fibres and disrupt the bonding. Thus in choosing the filler content of an uncoated paper a compromise has to be reached between the optical properties that the filler brings and the mechanical properties that it impairs (Phipps, 2001).

Figure 4 shows a simplified illustration of how this compromise is achieved. The $y$ axis represents the sheet weight (mass per unit area) required in order to achieve the target property, and the $x$ axis

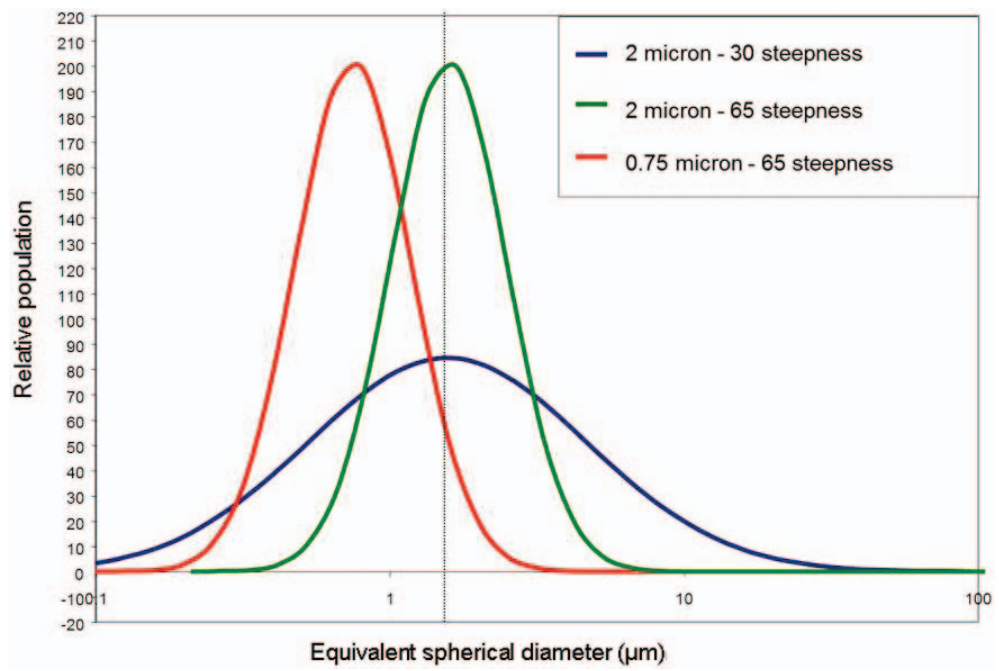

FIG. 2. Schematic representations of typical broad and steep particle size distributions of functional minerals. 


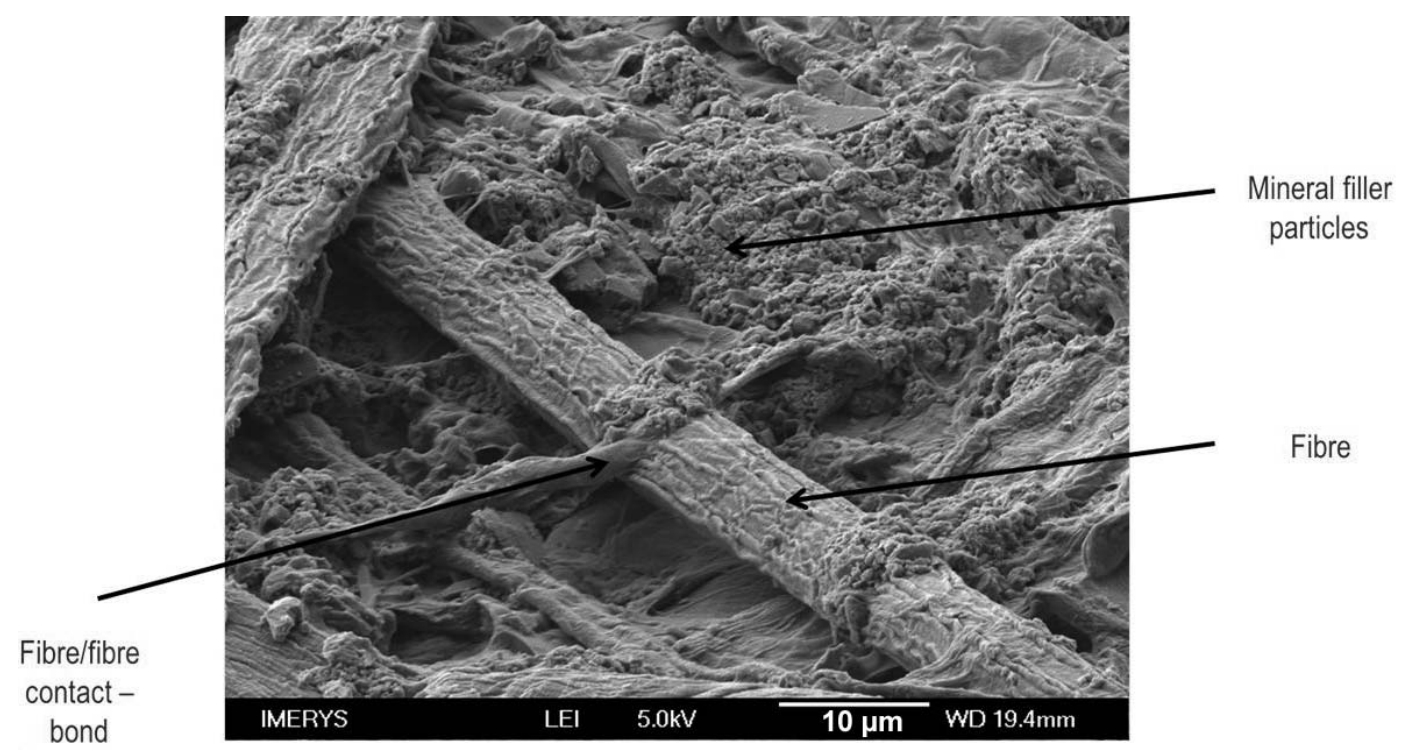

formation

FIG. 3. Scanning electron micrograph of the surface of an office printing and copying paper.

represents the mineral filler content by weight. With no mineral addition, a high sheet weight is required to reach the necessary opacity, but a much lower weight is required to reach the necessary strength. These weights are represented by the marks on the $y$ axis. As the mineral content increases, so the sheet weight needed for opacity decreases, but, because the filler weakens the sheet, the sheet weight needed for strength increases. Thus a line of sheet weight against filler loading at the target strength has a positive gradient and an equivalent line at the target opacity has a negative gradient. The point at which they intercept represents the sheet weight and filler content which just hits both targets and so is the optimum. So, for example, for a copy paper, which needs strength both in production and to behave correctly in photocopying/printing equip-

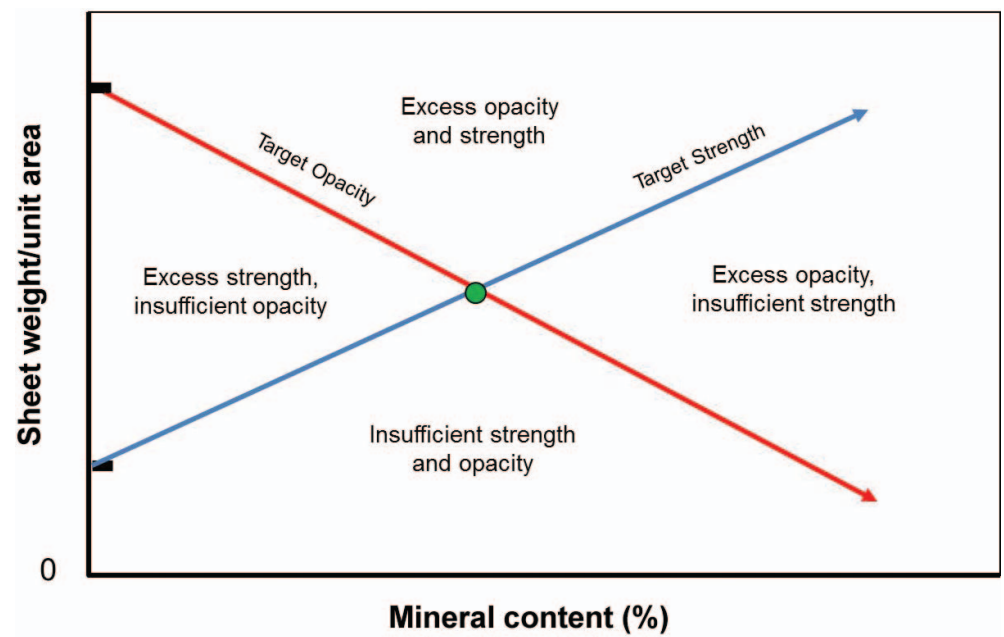

FIG. 4. Schematic representation of the effect of mineral content and sheet weight on paper optics and strength. 
ment, this would typically be at $80 \mathrm{~g} / \mathrm{m}^{2}$ (gsm) and $20-25 \%$ by weight of calcium carbonate filler. Significantly, standard paper grades have become defined by their sheet weight rather than by their specific properties.

The goal of the mineral supplier is to engineer the mineral to obtain the best compromise between final paper properties in order to give either the lowest cost/unit area, the lightest possible sheet weight, or, in many cases in which the grade has been defined at a particular gsm, the lowest cost per tonne. This generally means maximising the light scattering whilst minimising the loss of strength caused by the filler. As indicated above, the optimum light scattering occurs when the objects scattering the light (for uncoated papers this is mostly the fillers, but also the pores between them and the fibres) are close to its wavelength, which is around $0.5 \mu \mathrm{m}$ for visible light. Paper strength decreases with decreasing size and increasing specific surface area of the particles. Thus it is important to minimise the proportion of ultrafine (esd $<0.3 \mu \mathrm{m}$ ) particles, as these are too small to scatter light strongly and are extremely detrimental to paper strength. This compromise is typically achieved with a distribution in which the d50 is a little larger than the optimum for light scattering and the steepness is as high as the filler production costs will allow. For minerals whose size distribution is obtained by grinding or fractionation the finer sizes are more expensive as they require more grinding and/or separation energy, and steeper distributions cost more because they reduce the product yield from the raw material.

Figure 5 is a schematic showing the typical loss of strength per unit light scattering increase as mineral is added for a constant sheet weight. Note that fine minerals with a median size of $0.5-1 \mu \mathrm{m}$ tend to give more scatter at fixed strength than coarser ones with a median size of $2-3 \mu \mathrm{m}$ for the reasons outlined above. Thus if the main aim is to minimise the sheet weight or total material cost to hit a target performance fine minerals are generally preferred. Applications in which low weight is essential include directory papers, bible papers and instruction leaflets. However, in cases where the paper grade has become defined by the sheet weight this is not the main objective; costs are minimised by maximising the filler content because mineral fillers cost much less per tonne than fibres. Figure 5 shows that in these cases coarser fillers may be preferred because the targets can be reached at a higher filler content, even though it would also be possible to achieve them by using finer fillers and reducing the sheet weight (Fig. 6).

\section{Application 2 - coated paper}

Most high-quality papers are coated. Using a coating allows the papermaker to improve upon the strength/opacity compromise described in the previous section, because the required strength can be obtained from a base paper with a relatively low filler content, and the required optical properties

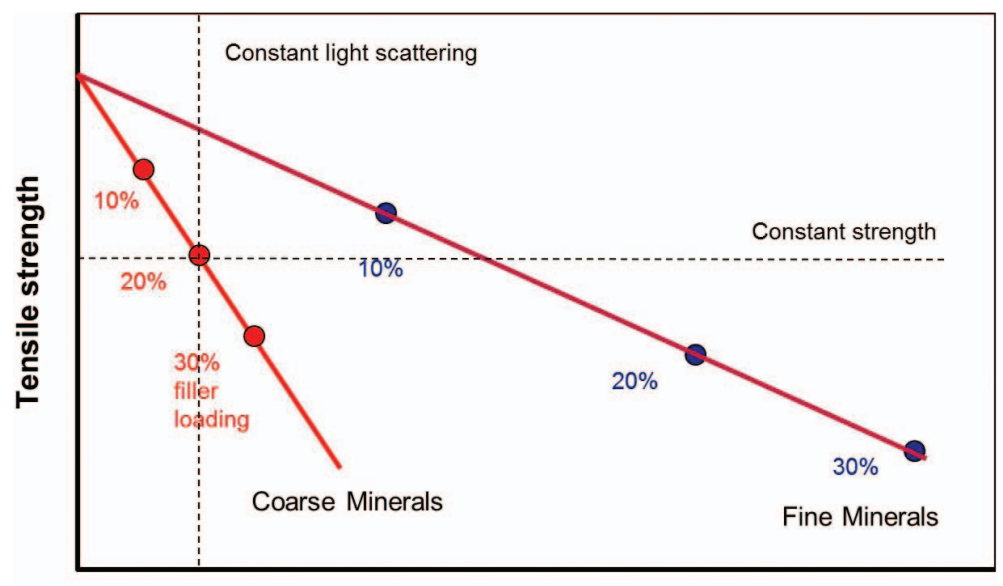

Light scattering coefficient

FIG. 5. Relationship between light scattering (opacity) and strength at different mineral addition levels for paper at constant sheet weight. 


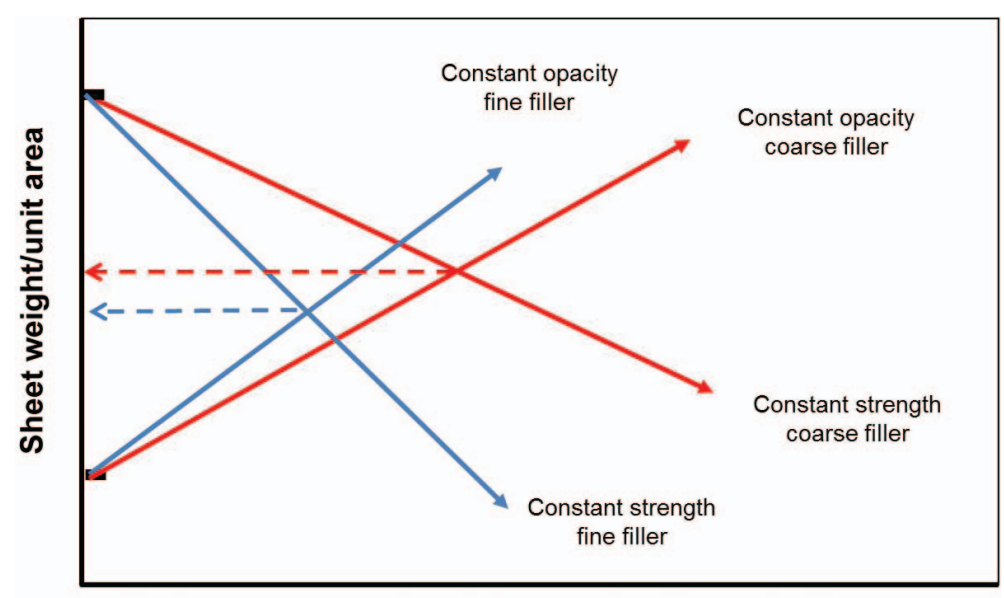

Mineral content (\%)

FIG. 6. Schematic representation of the effect of mineral particle size on sheet weight and mineral content required to reach ideal strength and opacity.

can be obtained from the coating. Paper coatings are comprised mostly of mineral particles, with either a polymer latex or starch (typically around $15 \%$ by weight) added to bind them together. Polymer latexes are made up from nano-sized particles which fuse together upon drying and bond with the mineral particles. Engineering a mineral to obtain optimum properties for coating involves a new set of compromises. The effects of the mineral on sheet strength are no longer important (though the amount of binder required to hold the coating together is), but its effects on the rheology profile of the coating formulation are critical, because paper coatings are applied at high speed and at the maximum solid content possible. Coating formulations (known as coating 'colours', despite being almost exclusively white) may be applied with a either a roller or a blade at speeds of up to $2000 \mathrm{~m} \mathrm{~min}^{-1}$, both of which impart very high shear at point of application (Clarke, 1997). However, formulations also need to be easily pumped to the coating applicator and circulated at low shear, so low viscosity over a wide shear range is necessary. A high solid content is required because the coated sheet must be dried very rapidly by infrared heaters before the paper is reeled up. Formulations must also be engineered to minimise penetration of the coating into the base paper as it is most effective on the surface. For the dry coating high opacity is desirable, as it is for uncoated papers, but good printing properties and a high level of gloss are also required.
Figure 7 shows scanning electron microscope images of the surface and the cross-section of a coated magazine paper. Note that the upper surface of the coating is much smoother than the base paper, because the thickness of the coating varies with the roughness of the substrate. The base paper has very little mineral content and a high proportion of large voids. The coating is comprised mainly of platy kaolin particles with some fine carbonate and binder visible. The pores between the particles are generally rather smaller than the kaolin particles; light scattering and thus the opacity of the coating is largely determined by these pores, and their size in turn is determined by the size and steepness of the mineral particle size distribution.

Figure 8 shows how paper opacity varies with median pore size (here measured by mercury porosimetry), and the effects of particle size and steepness on it (Nutbeem et al., 2005). The size of the pores is determined both by the size of the particles and the way in which they pack together, so steepness of the particle size distribution is also a key parameter. The product of median size and steepness gives a roughly linear relationship with median pore size. Pore size in broad distributions is generally smaller than in narrow ones because the finer particles can fit into the spaces between the larger ones. Within the range studied, larger pores give better opacity, but despite this minerals and pores need to be kept fine in order to give good gloss and to control ink uptake during printing.

Formulation rheology is also strongly influenced 

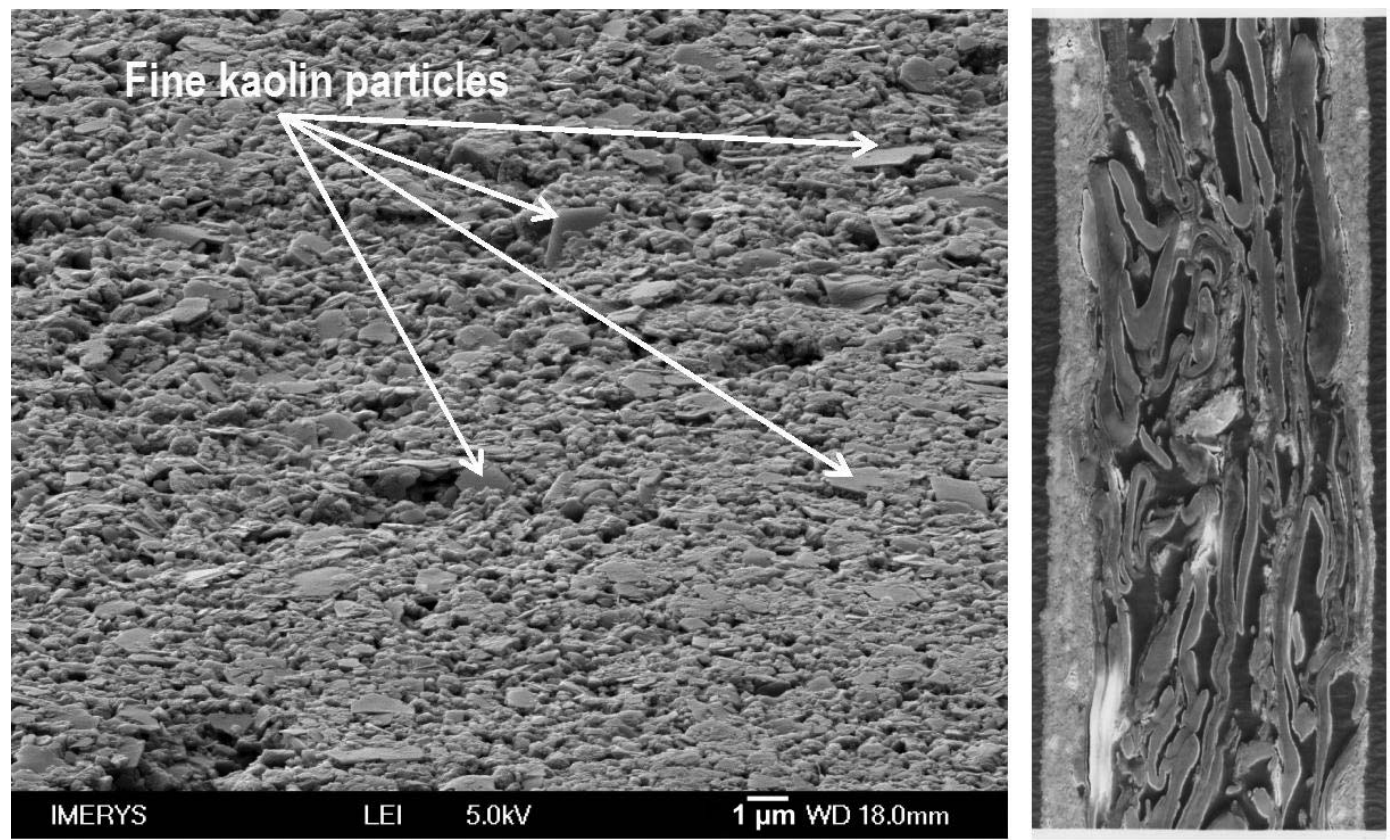

FIG. 7. Scanning electron micrographs of the surface (left) and cross section of a lightweight coated (LWC) magazine paper (right).

by the particle size distribution of the minerals. At low shear (relevant for pumping and for flow to/ round the coating head) it is dominated by the colloidal forces between the particles which are attractive at medium to long range, so finer minerals with larger surface area tend to have higher low shear viscosity. Packing effects are not particularly important at low shear, because the particles have adequate time to reorder and pack efficiently as they are disturbed by the flow. In contrast, at high shear the momentum of the particles overcomes the colloidal interactions so they are less important, and packing effects become much more significant as the particles do not have sufficient time to relax to their optimum structure. Therefore at high shear median particle size and surface area are not as important as steepness and particle shape. Highly anisotropic particles, such as kaolins, or very steep size distributions can lead to high viscosity and dilatancy at the shear rates
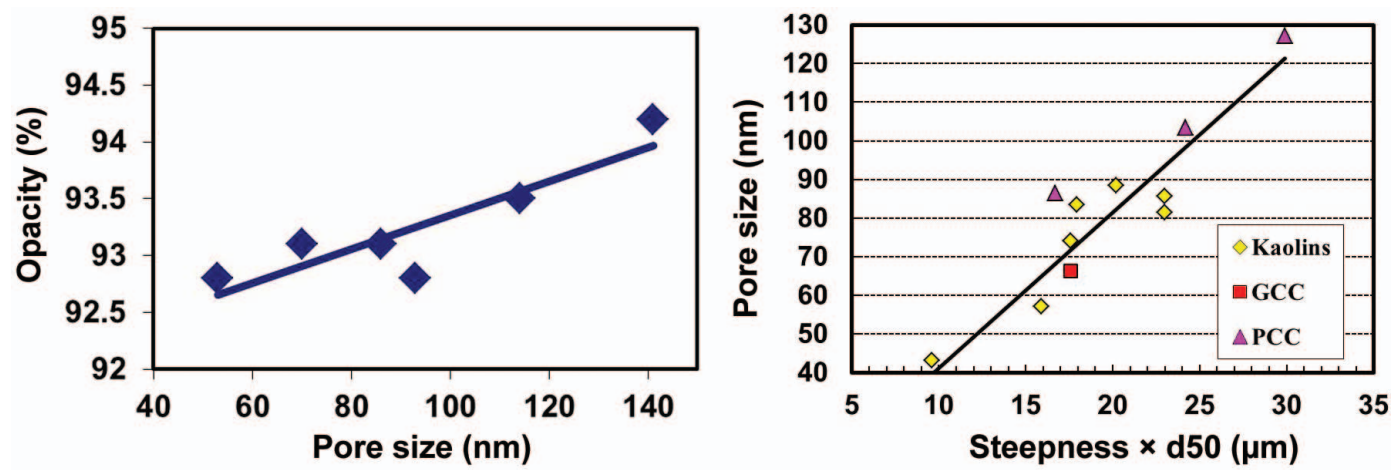

FIG. 8. Opacity $v s$. pore size (left) and pore size $v s$. mineral particle size distribution (right) for a range of paper coatings $(\mathrm{GCC}=$ ground calcium carbonate, $\mathrm{PCC}=$ precipitated calcium carbonate $)$. 
typically seen under a coating blade $\left(10^{6} \mathrm{~s}^{-1}\right)$ because the particles jam and cannot flow past each other. Thus at constant median size, increasing the steepness of a distribution will reduce the low shear viscosity because there will be fewer fine particles, but it will increase the high shear viscosity. Conversely at constant steepness reducing median size will greatly increase low shear viscosity, but have much less influence at high shear.

In addition to generating opacity and smoothness, paper coatings are usually required to give high sheet and print gloss, which places additional requirements on the minerals used. Gloss, defined as the fraction of parallel incident light which is reflected in a specular direction, is determined by the roughness of the surface at the microscale. Asperities which are similar in size to the wavelength of light will reduce it, so generally the finer the particles, the higher the gloss. In principle a broad distribution of particles will pack better and thus give better gloss, but it is often found that the presence of large particles which roughen the surface is the more significant factor, so that for a given median size a narrower distribution is better.

Figure 9 shows the effect of median size on gloss for coatings containing only kaolin as the mineral component, applied at a constant coat weight onto a magazine base paper. The narrow (steep) distribution gives the higher gloss at each median size, but the difference is almost eliminated for the finest samples, as particles in the broad distributions that are significantly larger than the wavelength of light are progressively eliminated.

One further important factor in the generation of paper gloss is the degree to which the coating is

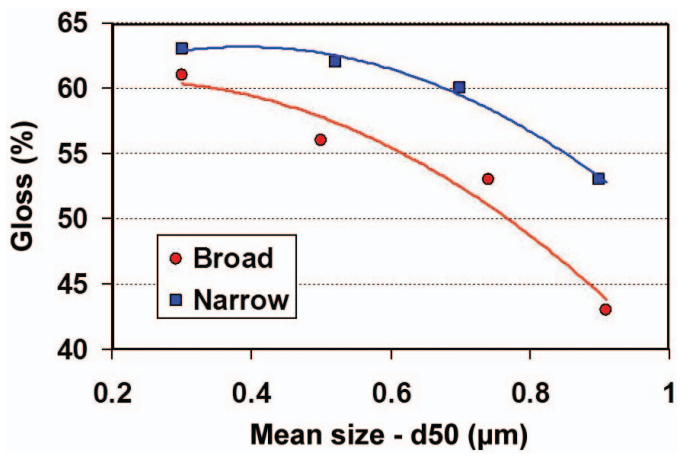

FIG. 9. Gloss vs. median particle size for LWC magazine papers coated with $100 \%$ kaolin-based formulations. held on the surface, which is often referred to as 'coverage'. Fine and blocky mineral particles in particular may penetrate deep into the base paper during coating, and thus become effectively lost to the coating. For this reason, high aspect ratio clays are most widely used at very low coat weights, as the high diameter of the particles prevents them from penetrating the substrate, particularly as they tend to be aligned parallel to the surface by the shear flow during application. Steep distributions will also generally give better coverage than broad ones as they contain fewer ultrafine particles. Figure 10 illustrates this effect - at very low coat weights, a relatively coarse (but very platy) kaolin gives higher gloss than a much finer, lower aspect ratio clay, whereas at high coat weights the latter gives the best performance because there is sufficient material to cover the surface well despite the loss of some of it into the sheet. In high quality coated grades multiple coatings may be used; a platy kaolin forms the basis of the precoat in order to obtain good coverage, and a fine calcium carbonate may then be used for the topcoat to generate the maximum gloss.

As well as high sheet gloss, premium quality papers also require high print gloss. This is largely determined by the same factors as the paper gloss, but it can be reduced if the surface is too porous and ink is drawn down into the coating too far before it sets. This problem is most acute for fast setting, low viscosity inks, which are necessary for high speed printing (Preston et al., 2002). To prevent it, platy clays may often be incorporated into formulations to help reduce the porosity of the surface. Whilst this may reduce the paper gloss a little, its effect on print gloss makes it an acceptable compromise.

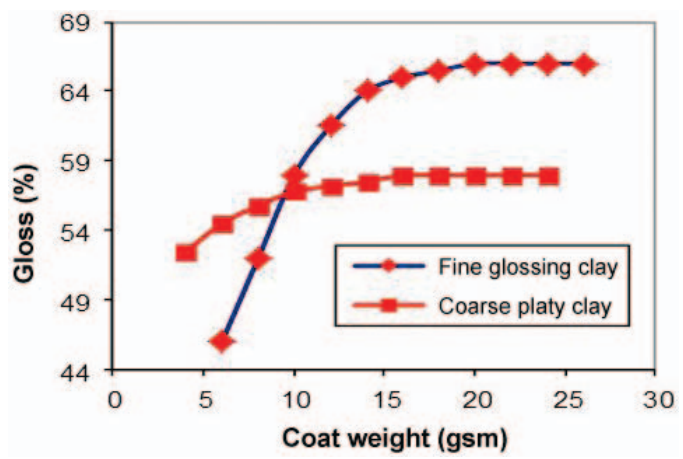

FIG. 10. Effect of particle shape on sheet gloss as a function of coat weight on LWC magazine paper. 


\section{Application 3 - decorative paint}

Decorative paints, which we shall define as those used in interior wall and ceiling coatings whose main purpose is not protective, are similar in composition and aim to paper coatings. There are of course some key differences; paints need to be much more resistant to scrubbing, staining and other damage than paper coatings, they need to have higher opacity as they may have to cover quite dark surfaces, and high gloss is not required. To achieve durability, paints usually contain much more binder than paper coatings; the binder must also be water resistant after drying. Paint binders are typically made from polymer latex particles which are very similar to those used in paper coatings, and which fuse together upon drying and fill up the space between the mineral particles. At a critical mineral/binder ratio, known as the critical pigment volume concentration (CPVC) (Asbeck \& Loo, 1949), there is just enough binder to fill all of the space between the mineral particles. At binder additions below this level (i.e. for paints formulated above the CPVC) the paint film will thus contain air voids (Fig. 11). Many properties, such as the film permeability and opacity, change rapidly around this point.

Most matt and semi-gloss paints are formulated so that the dried film is above the CPVC, and they contain sufficient air to contribute to the opacity of the paint (Paul, 1996). However, the amount of air in the coating, and thus the potential for light scattering from the pores, is much lower than in paper coatings, so paints also contain titanium dioxide particles $\left(\mathrm{TiO}_{2}\right)$ to increase their opacity. $\mathrm{TiO}_{2}$ has a very high refractive index (2.5 to 2.7, depending upon the grade and the wavelength used for the measurement) and so can generate strong light scattering even when completely surrounded by latex or other mineral particles. Paint grade $\mathrm{TiO}_{2}$ is made synthetically and consists of spherical particles with a median size of around $0.3 \mu \mathrm{m}$ and a very high steepness (Braun et al., 1992). This size is used in order to generate the maximum possible light scattering; the optimum is dependent upon both wavelength and refractive index. Most functional minerals, by contrast, have a similar refractive index to the binders $(\sim 1.5)$, and thus only generate significant scattering when in contact with air. For this reason, the majority of functional mineral use is in decorative coatings formulated above the CPVC.

Gloss paints are typically formulated below the CPVC. The voids between the particles at the surface become filled with binder, and surface tension effects will tend to exclude larger particles from the wet surface and thus lead to a smooth surface and high gloss. The presence of coarser particles also reduces gloss, but not as significantly as in paper coatings. Furthermore, because mineral particles contribute little to light scattering below the CPVC, they are not used so extensively in gloss coatings, though they do have a role in reducing the amount of expensive binder used and in optimizing the performance of the $\mathrm{TiO}_{2}$. Scattering from the $\mathrm{TiO}_{2}$ may be reduced by the phenomenon of optical crowding, which occurs when the particles get too close to each other. If this happens then the mean refractive index around each particle rises and the effective contrast is reduced, and thus so is the light scattering generated. This effect is most significant in coatings in which there is a high level of $\mathrm{TiO}_{2}$, although as will be seen it can also be a problem in decorative paints. The use of a suitable functional mineral 'extender' can reduce it substantially.

Figure 12 shows the surface of a typical matt decorative paint. This example was formulated with a combination of coarse and fine calcium carbonate particles (d50 of $7 \mu \mathrm{m}$ and $2.5 \mu \mathrm{m}$ respectively), ultrafine kaolin $(\mathrm{d} 500.5 \mu \mathrm{m})$ and $\mathrm{TiO}_{2}$. The coarse particles help keep the cost of the paint low and also contribute to the surface roughness, reducing the gloss as required for a matt finish. The ultrafine platy kaolin extenders help to create the right pore structure for opacity and also have a key role in spacing the $\mathrm{TiO}_{2}$ particles and preventing optical

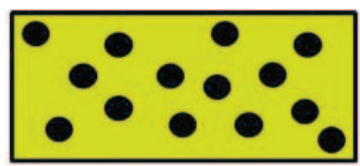

Below CPVC

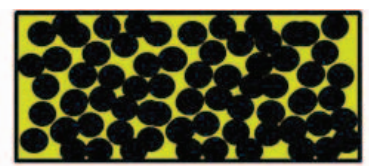

At CPVC

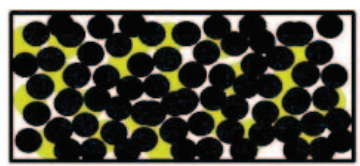

Above CPVC

FIG. 11. Schematic diagram demonstrating the Critical Pigment Volume Concentration (CPVC). Black circles represent mineral particles, yellow fill represents binder and white represents air. 


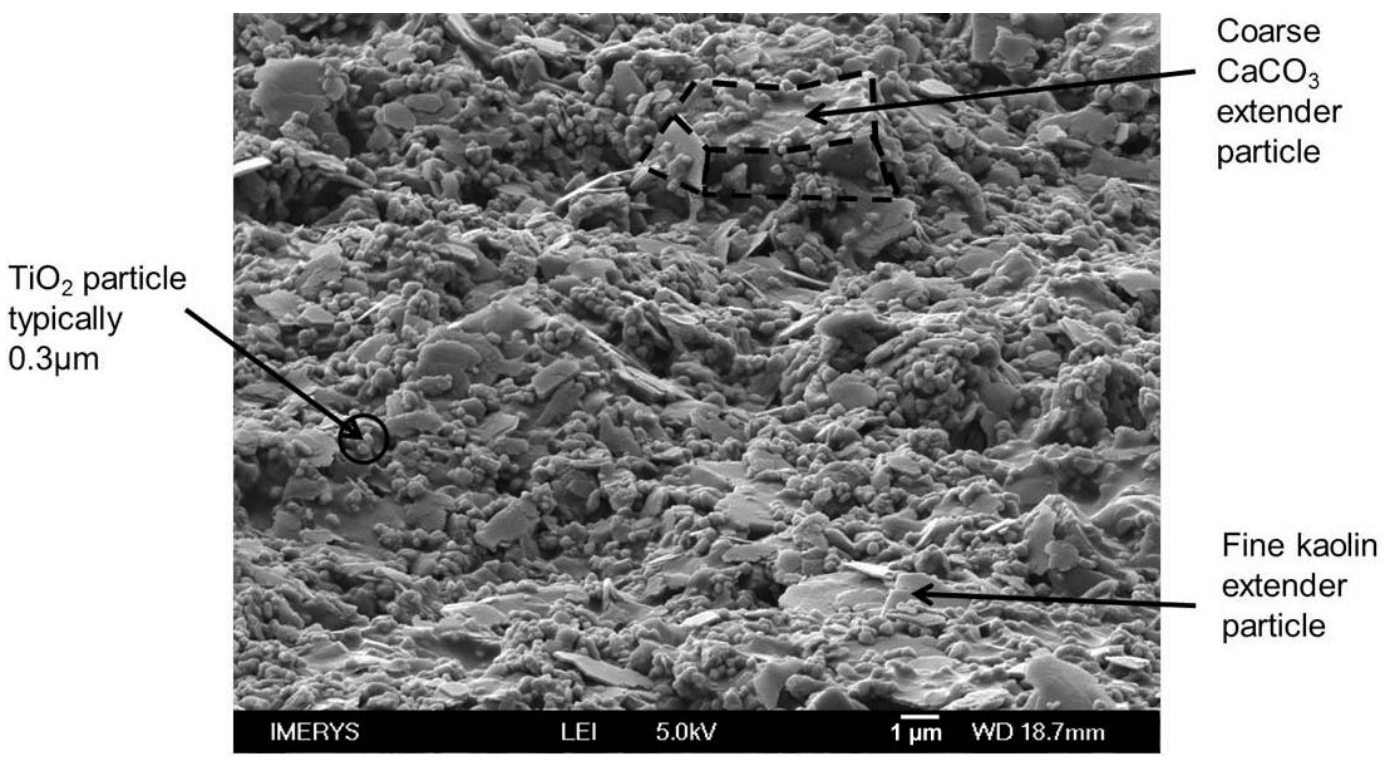

FIG. 12. Scanning electron micrograph of the surface of a matt interior decorative paint.

crowding. Figure 13 is a schematic which demonstrates the standard hypothesis of how this occurs. If coarse particles are used alone they force the $\mathrm{TiO}_{2}$ particles to associate together in the spaces between them. If fine particles, with one dimension or more similar to the $\mathrm{TiO}_{2}$, are used instead, they can be distributed between the $\mathrm{TiO}_{2}$ particles and force a more uniform distribution. This can be done with ultrafine blocky or spherical particles of similar diameter to the $\mathrm{TiO}_{2}$, or with platy kaolin particles which have a much larger diameter but similar thickness.

Figure 14 shows the effect of an optimised extender, in this case a fine, platy kaolin, in reducing optical crowding in a paint formulated below the CPVC. The idealised formulation was made initially with just a styrene-acrylic latex binder and a well dispersed $\mathrm{TiO}_{2}$. At volume fractions of up to $10 \%$, the increase in scattering coefficient with $\mathrm{TiO}_{2}$ content, derived from paint reflectance via Kubelka-Munk theory (Kubelka \& Munk, 1931; Kortum, 1969), is linear, demonstrating that optical crowding is not significant in this region. Above $10 \%$ the increase levels off as the particles begin to interfere with each other. A single formulation made at $18 \%$ volume fraction with a flocculated $\mathrm{TiO}_{2}$ suspension confirms the effect, as its scattering is considerably reduced compared with the dispersed example at the same level. If a platy kaolin is mixed with the $\mathrm{TiO}_{2}$ at a ratio of $30 \%$ by volume, the scattering is essentially identical to the $\mathrm{TiO}_{2}$ alone at low volume fraction (indicating the negligible contribution of the kaolin itself to light scattering below the CPVC), but is significantly higher at high volume fraction.

\section{Application 4 - Filled thermoplastics}

Industrial minerals are also used widely in many common thermoplastics such as polyethylene,

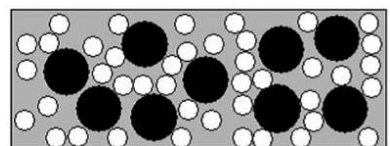

$\mathrm{TiO}_{2} \&$ coarse mineral

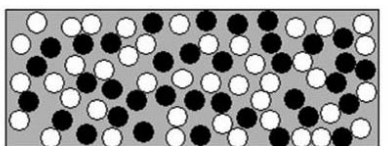

$\mathrm{TiO}_{2} \&$ fine mineral

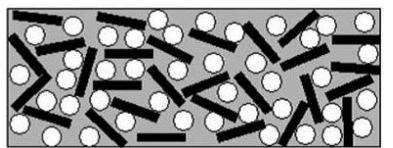

$\mathrm{TiO}_{2} \&$ lamellar mineral

FIG. 13. Schematic of the effect of different mineral sizes and shapes on the spacing of $\mathrm{TiO}_{2}$ particles in paint. 


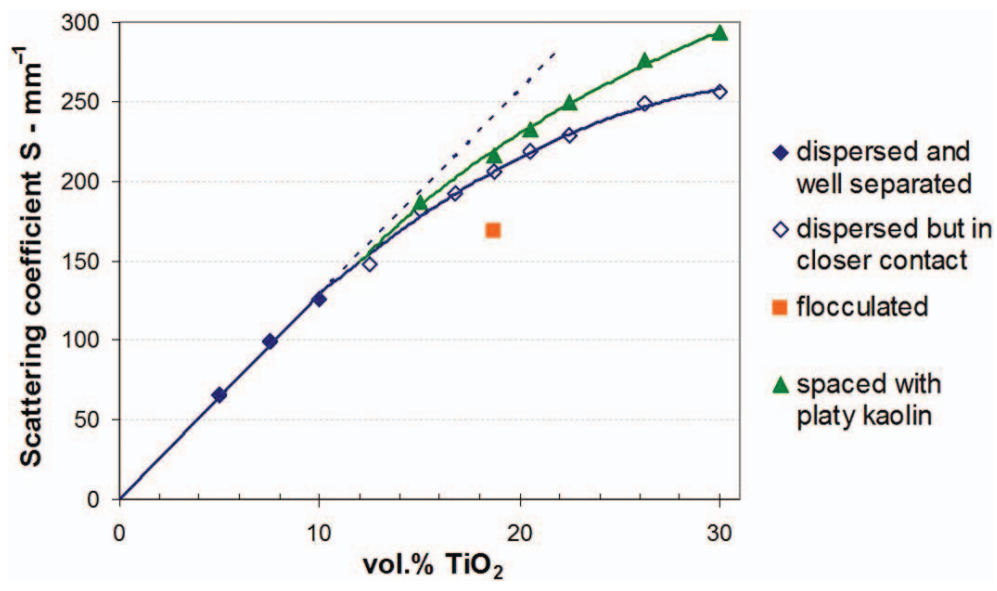

FIG. 14. Effect of a mineral extender on the light scattering coefficient of a paint film below $\mathrm{CPVC}$ as $\mathrm{TiO}_{2}$ content is increased. $\mathrm{TiO}_{2}$ only (blue diamonds); $\mathrm{TiO}_{2}$ with $30 \%$ platy kaolin (green triangles).

polypropylene, polyamides and PVC (Katz \& Mileski, 1997; Rothon, 2001; Xanthos, 2010). Although the cost per tonne of the mineral is in most cases considerably less than the polymer, they are not typically added to save cost, but rather to improve the physical properties of the polymer. The use of minerals increases the polymer stiffness and reduces its thermal expansion coefficient, and also aids in the processing of the polymer melt by reducing its viscosity and increasing its thermal conductivity. This leads to shorter cooling times and thus faster cycles through injection moulding, film blowing, etc. (Rothon, 2003).

Compared with paints and paper coatings, the mineral content of plastics is very low. Minerals can be used at up to $50 \%$ by weight or approximately $30 \%$ by volume. They are therefore present at substantially below the CPVC, so their optical effects are not very significant because, as in paints, the refractive index of the mineral is close to that of the surrounding polymer medium. Furthermore, plastic articles (with the exception of film products) are usually quite thick, so if whiteness or opacity is needed it can be achieved with addition of $\mathrm{TiO}_{2}$ at a level substantially below the onset of optical crowding effects.

Figure 15 shows the effect of a fine particle size calcium carbonate filler on the flexural modulus (stiffness ) of a typical polypropylene polymer. At an addition level of $30 \%$ by volume, it is more than doubled, and there is an approximately linear relationship between it and the amount of mineral added. The composite modulus can thus be expressed as the weighted sum of the polymer modulus and an effective filler modulus, but it should be noted that the latter is much less than the true modulus of the mineral. Theoretical models have been derived which aim to explain this, and which define the effective modulus in terms of the actual mineral modulus, its aspect ratio and the

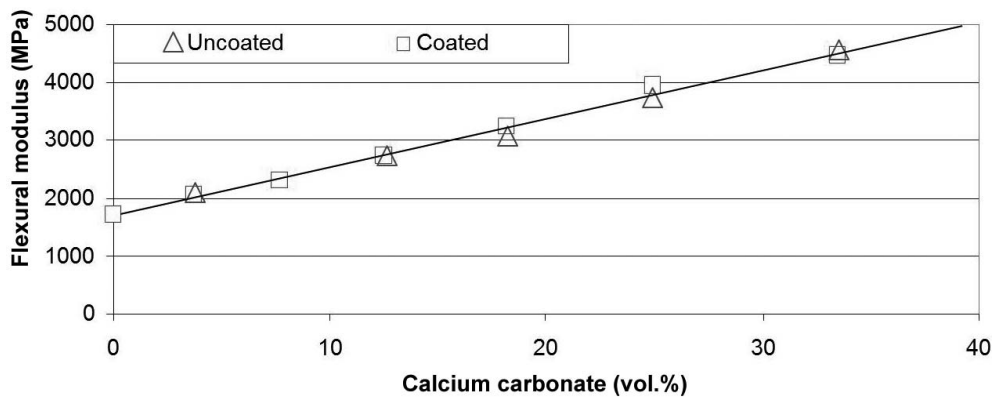

FIG. 15. Effect of calcium carbonate addition on the flexural modulus of a polypropylene polymer. 
elastic properties of the polymer matrix in which it is used (Padawer \& Beecher, 1970). Perhaps surprisingly in the light of the mineral applications discussed so far, particle size does not significantly influence stiffness. Figure 15 also shows that the nature of the filler/polymer interface does not significantly affect the stiffness of the composite as it is the same whether an uncoated mineral or one coated with stearic acid to render it compatible with the polymer is used. However, minerals used in polymers are often coated for a number of reasons. Surface coating can improve the wetting and dispersion of the mineral during compounding with the polymer by reducing the interfacial energy and eliminating moisture, and bonding between the polymer and the mineral particles also affects the tensile and impact strength of the composite (Ahsan \& Taylor, 1998).

Figure 16 shows the influence of particle aspect ratio on composite stiffness in a similar grade of polypropylene. Aspect ratio (the ratio of particle diameter to thickness) of particulate minerals is difficult to measure, but using various techniques (Webb \& Gate, 1996; Hart et al., 2011) an average value may be obtained which agrees well with microscopy images. A very high aspect ratio $(\sim 150)$ mica gives a fivefold increase in modulus at $40 \%$ addition by weight, whereas the blocky calcium carbonate increases it by less than a factor of two.

When adding mineral fillers to thermoplastic polymers, a compromise has to be made between the stiffness and impact strength of the composite. Impact failure is a complicated process that involves the initiation and propagation of fractures, and the role of the mineral in both of these is very important (Jancar et al., 1992). As a general rule, the larger the major dimension of a particle, the more tendency it has to induce defects where fracture initiation can occur, and thus the lower the resulting impact strength. In order to obtain the high particle aspect ratio that is required for high stiffness of the composite, it is usually necessary to have particles whose major dimension is large compared with low aspect ratio particles of similar volume, and so high modulus normally has to be traded against low impact strength.

For commercially available mineral fillers for polymers, the relationship between modulus and impact strength can appear as a universal curve onto which all of the mineral products fit. Figure 17 shows the flexural modulus of polypropylene against one measure of impact strength (ISO 179-1, notched charpy) for a wide range of commercial fillers to illustrate this. However, the curve is not truly universal since all of the products have been optimized to obtain a particular compromise. It is simple enough to obtain a combination of poorer properties; for example very coarse blocky particles will give both low modulus and poor impact strength. To maximise impact strength requires very fine particles with a maximum dimension of $0.5 \mu \mathrm{m}$ or less; high aspect ratio is hard to obtain at such a small size and thus the highest impact strength is not accompanied by the highest modulus. Likewise the highest aspect ratio particles such as micas may be only a few hundred nanometres thick but still have a diameter in the range of $40 \mu \mathrm{m}$ and thus give poor impact strength.

The above discussion does suggest, however, that if a very high aspect ratio can be combined with ultrafine particles then a better compromise might

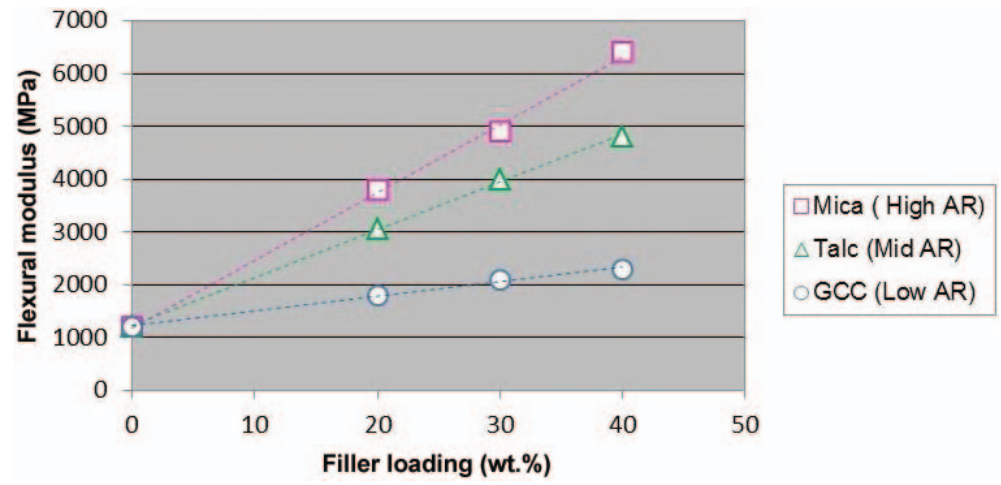

FIG. 16. Effect of particle aspect ratio (AR) on the flexural modulus of polypropylene $(\mathrm{GCC}=$ ground calcium carbonate). 


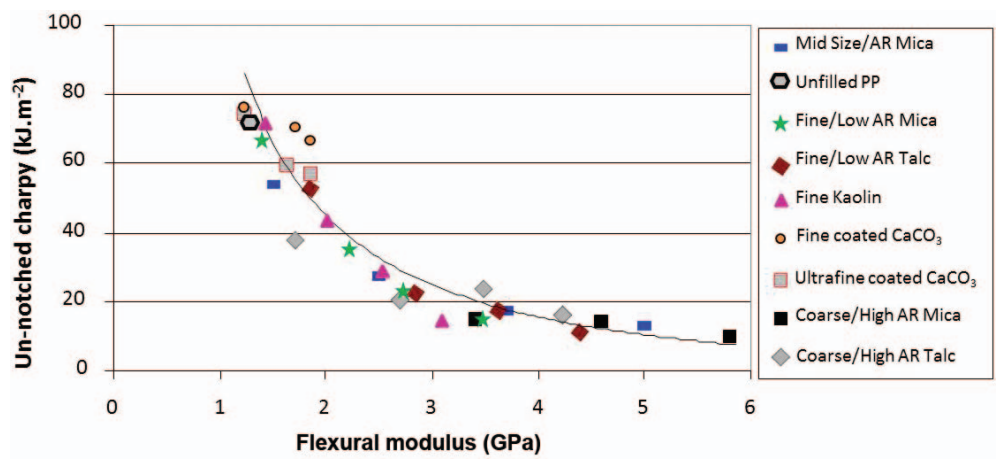

FIG. 17. Measured impact strength against flexural modulus for a range of mineral/polypropylene composites.

be achieved. The use of 'nanoclays' (fully exfoliated montmorillonite or vermiculite) has attracted much interest in recent years, as early results promised exceptional properties at low addition levels (Fukushima \& Inagaki, 1987). If exfoliated completely, these clay minerals can be reduced to individual 2:1 layers around $1 \mathrm{~nm}$ thick. However, dispersion down to the individual sheets is extremely difficult and has greatly restricted their adoption in commercial products. Furthermore, at this size the particles are similar to or smaller than individual polymer molecules, so their influence on polymer conformation and crystallinity may be equally significant in determining the final properties of the composite.

Mineral fillers are also commonly added to polymer films for a variety of applications including packaging (Arina et al., 1979; Schut, 2006) and agriculture (Espi et al., 2006). The same structure/property relationships apply to polymer films as to the bulk materials, but a few other properties become important here as well. For many packaging applications high transparency and clarity is required, which limits the amount of mineral that can be used and generally requires a close refractive index match between the mineral and polymer and/or very fine particle size. One of the important film applications of minerals is as 'antiblocks', in which a coarse mineral (d50 of around $10 \mu \mathrm{m}$ ) is used at low concentration to roughen the surface of the film. This prevents films that come into close contact, for example in plastic bags, from sticking to each other. Low bulk density minerals such as diatomaceous earth and expanded perlite are commonly used; these have large external dimensions and high internal porosity which makes them very effective at the low concentrations $(<1000 \mathrm{ppm})$ required to maintain sufficient transparency and clarity.

Very fine minerals can be used to improve tear strength of films as they arrest microcracks and prevent them from developing into larger defects. For this they need to be well bonded to the polymer and very well dispersed, and hence they perform best at low addition levels (Fig. 18). Above this the particles will begin to form clusters in an analogous manner to $\mathrm{TiO}_{2}$ in paint discussed earlier; these clusters behave as larger particles and no longer arrest microcracks effectively.

Sometimes defects in the film are actually desired - their presence is exploited in manufacture of cheap, breathable plastic films which are used in the coverings for diapers and in 'building wrap' insulation products. Typically a fine coated calcium carbonate is used at very high loading level (up to $50 \mathrm{wt.} \%)$. The critical role of the mineral coating is

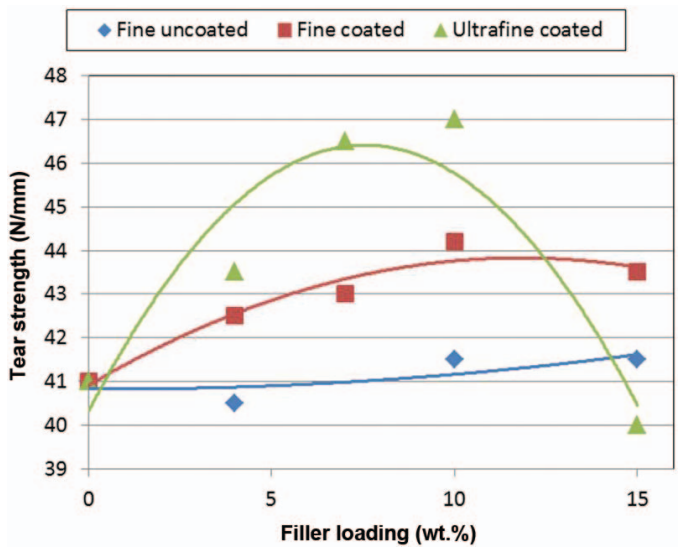

FIG. 18. Effect of various calcium carbonate minerals on the tear strength of polyethylene film. 


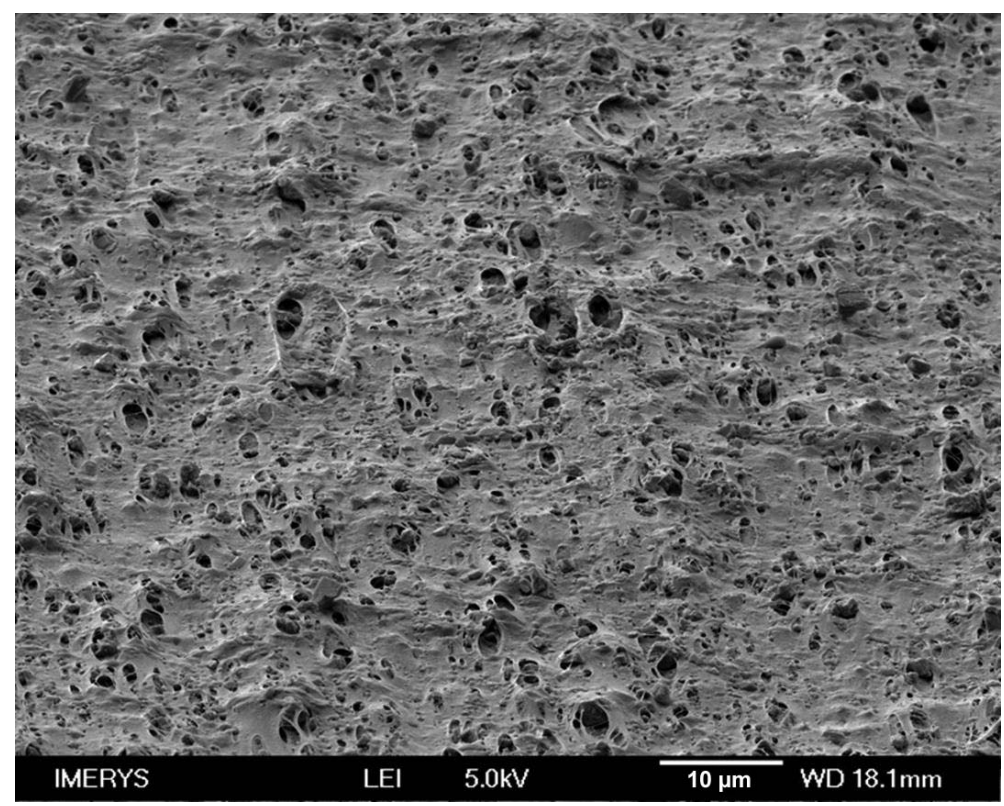

FIG. 19. Scanning electron micrograph of the surface of a calcium carbonate-filled, biaxially stretched breathable polyolefin film.

to allow efficient dispersion of the particles into the polymer during compounding, but not to form a strong bond between the particle and polymer. The compounded polymer is subsequently extruded and blown into a film; once cooled the film is biaxially stretched, forcing the polymer to de-bond from the particles to form micro-pores which give the film its breathability (Fig. 19). Control of particle size is also key in order to get the optimum size of pores for breathability without inducing failure during stretching.

\section{SUMMARY AND OUTLOOK}

In this paper it has been shown how industrial minerals producers manipulate the properties of natural minerals such as particle size, shape and surface coating to generate desirable properties in a diverse range of applications. Despite this diversity, there are many common themes such as light scattering, particle dispersion, porosity and reinforcement which apply to quite different applications. The majority of applications in which industrial minerals are used are in mature industries, and the materials have remained fairly constant for a long time. For these industries, the job of the mineral producer is to keep producing the same quality of product from ever-changing reserves and with ever- reducing costs. Although the basic role of the mineral additives remains the same, often the products have to change as the applications adapt - for example in the paper industry, where uses of paper and printing techniques are in rapid flux as more information is stored and distributed electronically and printing methods are changing from the bulk to the personal and digital. As energy costs rise and environmental issues gain prominence there are fresh challenges in production in adapting minerals to recycled materials (plastics, paper) and even recycling the minerals themselves. For the producers of industrial minerals, a constant R \& D effort is required both to keep up with these challenges and to find new applications where the properties of these basic raw materials can be beneficial.

\section{ACKNOWLEDGMENTS}

My thanks go to the many colleagues who have provided information, data and advice during the preparation of this manuscript: John Husband, John Slater, Janet Preston, Chris Paynter, Tony Hiorns, Chris Nutbeem, Gary Sleeman, Anabelle Legrix and Beverley Dingle, and to Imerys for permission to present and publish the paper. 


\section{REFERENCES}

Ahsan T. \& Taylor D.A. (1998) The influence of surface energetics of calcium carbonate minerals on mineralpolymer interaction in polyolefin composites. The Journal of Adhesion, 67, 69-79.

Arina M., Honkanen A. \& Tammela V. (1979) Mineral fillers in low densitypolyethylene films. Polymer Engineering \& Science, 19, 30-39.

Asbeck W.K. \& Loo M.V. (1949) Critical pigment volume relationships. Industrial \& Engineering Chemistry, 41, 1470-1475.

Bates R.L. (1994) Overview of the industrial minerals. Pp. 3-5 in: Industrial Minerals and Rocks, 6th ed. (D.D. Carr, editor) Society for Mining, Metallurgy, and Exploration, Inc., Littleton, Colorado.

Bown R. (1985) The relationship between strength and light scattering coefficient for filled papers. Papermaking Raw Materials, 2, 543-576.

Bown R. (1995) Physical and chemical aspects of the use of fillers in paper. Pp. 194-230 in: Paper Chemistry. Springer, Netherlands.

Braun J.H., Baidins A. \& Marganski R.E. (1992) $\mathrm{TiO}_{2}$ pigment technology: a review. Progress in Organic Coatings, 20, 105-138.

Brown D.J., Vickers G.T., Collier A.P. \& Reynolds G.K. (2005) Measurement of the size, shape and orientation of convex bodies. Chemical Engineering Science, 60, 289-292.

Clarke J.B. (1997) Rheology modifiers and pigment dispersants. Pp. 109-128 in: Surface Application of Paper Chemicals (I. Thorn, editor). Springer.

Espi E., Salmeron A., Fontecha A., García Y. \& Real A.I. (2006) Plastic films for agricultural applications. Journal of Plastic Film and Sheeting, 22, 85-102.

Fukushima Y. \& Inagaki S. (1987). Synthesis of an intercalated compound of montmorillonite and 6polyamide. Journal of Inclusion Phenomena, 5, 473-482.

Hart J., Zhu Y. \& Pirard E. (2011) Particle size and shape characterisation - Current technology and practice. Pp. 77-127 in: Advances in the Characterization of Industrial Minerals (G.E. Christidis, editor). EMU Notes in Mineralogy, 9. European Mineralogical Union, Mineralogical Society of Great Britain and Ireland.

ISO 179-1 (2010) Plastics - Determination of Charpy impact properties - Part 1: Non-instrumented impact test.
Jancar J., Dianselmo A. \& Dibenedetto A.T. (1992) The yield strength of particulate reinforced thermoplastic composites. Polymer Engineering \& Science, 32, 1394-1399.

Jennings B.R. \& Parslow K. (1988) Particle size measurement: the equivalent spherical diameter. Proceedings of the Royal Society of London. A. Mathematical and Physical Sciences, 419, 137-149.

Katz H.S. \& Mileski J.V., editors (1987) Handbook of Fillers for Plastics. Springer.

Kortüm G. (1969) Chapter IV in: Reflectance Spectroscopy: Principles, Methods, Applications. Springer.

Kubelka P. \& Munk F. (1931) A contribution to the optics of pigments. Zeitschrift für Technische Physik, 12, 593-599.

Nutbeem C., Husband J.C. \& Preston J.S. (2005) The role of pigments in controlling coating structure. Pp. 97-102 in: PITA Coating Conference, Bradford, Proceedings.

Padawer G.E. \& Beecher N. (1970) On the strength and stiffness of planar reinforced plastic resins. Polymer Engineering \& Science, 10, 185-192.

Paul S. (1996) Surface coatings - Science \& Technology, $2^{\text {nd }}$ ed., John Wiley \& Sons.

Paulapuro H. (2000) Paper and Board Grades. Book 18. Helsinki, Fapet Oy.

Phipps J. (2001) Choosing fillers for optimum paper properties: understanding the compromises. Paper Technology, 42, 37-41.

Preston J.S., Elton N.J., Legrix A., Nutbeem C. \& Husband J.C. (2002) The role of pore density in the setting of offset printing ink on coated paper. TAPPI Journal, 1, no. 3, 3-5.

Rothon R. (2001) Particulate Fillers for Polymers (Vol. 12). iSmithers Rapra Publishing.

Rothon R.N., editor (2003) Particulate-filled Polymer Composites. iSmithers Rapra Publishing.

Schut J.H. (2006) More filler, less resin: Bag films load up to cut costs. Plastics Technology, 52, 38-43.

Slepetys R.A. \& Cleland A.J. (1993) Determination of shape of kaolin pigment particles. Clay Minerals, 28, 495-508.

Webb T.W. \& Gate L.F. (1996) U.S. Patent No. 5,576,617. Washington, DC: U.S. Patent and Trademark Office.

Xanthos M., editor (2010) Functional Fillers for Plastics. John Wiley \& Sons. 